\title{
Effects of Thermal Shields on Temperature of a Hot Steel Strip in Rolling Process
}

\author{
Sang Hyun PARK, ${ }^{1,2)}$ In-Beum LEE ${ }^{3)}$ and Euntaek LEE ${ }^{4) *}$ \\ 1) Thermo-Fluid \& Process Research Group, Technical Research Laboratories, POSCO, Pohang, 37859 Republic of Korea. \\ 2) Graduate School of Engineering Mastership, Pohang University of Science and Technology, Pohang, 37673 Republic of Korea. \\ 3) Graduate Institute of Ferrous Technology, Pohang University of Science and Technology, Pohang, 37673 Republic of Korea. \\ 4) Department of Mechanical System Engineering, Kumoh National Institute of Technology, Gumi, 39177 Republic of Korea.
}

(Received on October 28, 2019; accepted on January 28, 2020)

\begin{abstract}
The temperature of the hot steel strip between roughing and finishing mills is important parameter to manufacture the high-quality products. It has great influences on mechanical properties and manufacturing costs of the steel products. The hot steel strip between roughing and finishing mills has considerable heat loss and temperature drop due to the exposure to cold environment and air. The thermal shield is required to reduce the heat loss and temperature drop of the hot steel strip. Thus, the model prediction for the temperature of the hot steel strip is developed to design the thermal shield and identify its effects. The experiment for the hot steel strip sample is performed to validate the model prediction. The results of the experiment and model prediction have the good agreement for different emissivity and temperature of the thermal shields. In addition, the temperature variation and distribution of the hot steel strip between roughing and finishing mills is predicted for different geometries of the thermal shields. The thermal shield with low emissivity and high temperature reduces the temperature drop of the hot steel strip for practical purposes.
\end{abstract}

KEY WORDS: hot steel strip; hot rolling process; thermal shield; temperature variation; emissivity.

\section{Introduction}

Rolling is an essential process to shape the materials in the steel industry. The hot steel strip at temperature higher than $1000^{\circ} \mathrm{C}$ is passed through the counter rotating rollers and its thickness is reduced. The temperature of the hot steel strip has great influences on mechanical properties of the steel products and is important parameter to manufacture the high-quality products. ${ }^{1-4)}$ The uniformity of the mechanical properties also depends on the temperature distribution of the steel strip. Measuring the temperature is a common method to identify the temperature distribution of the steel strip. ${ }^{5,6)}$ However, it is limited to the surface temperature of the strip and not applicable to the fast-moving steel strip. ${ }^{7,8)}$ Therefore, the numerical simulation of the temperature distribution for the hot steel strip has been developed. ${ }^{9-13)}$

Generally, the temperature of the steel strip decreases when it moves from one process to another through the transfer table. The hot steel strip is exposed to cold environment and air and has heat losses during the processes. ${ }^{14-16)}$ Especially, the great heat losses occur between roughing and finishing mills. The heat losses need to be reduced for the product quality and cost. The thermal shield between roughing and finishing mills is employed to reduce the radiative heat losses. ${ }^{17)}$ Many studies were conducted for measuring and simulating the steel strip temperature and the effects of

* Corresponding author: E-mail: euntaek@kumoh.ac.kr

DOI: https://doi.org/10.2355/isijinternational.ISIJINT-2019-687 the thermal shield.

Panjkovic $^{18)}$ developed a comprehensive model to predict the temperature of the steel strip using finite difference method. The author considered radiative and convective heat losses, forced flow boiling and film boiling of water at strip surface, deformation heat in the roll gap, frictional sliding heat, heat of scale formation and the heat transfer between strip and work rolls through an oxide layer between the roughing and finishing mills exit.

Han et al. ${ }^{19)}$ used a finite element method to develop a numerical model to simulate the deformation, temperature and phase transformation behavior in both thickness and width direction of strip on a run-out table (ROT) in hot strip mill. The authors compared the calculated temperature-phase-deformation behavior with the measured data and achieved good agreement.

Mei et al. $^{20)}$ calculated the temperature distribution in hot strip rolling process by finite element method. The authors considered the heat transfer coefficients of air cooling, water cooling and thermal resistance between work roll and strip and proposed a new heat generation rate model in the induction heating. They investigated the influence of the induction heating on the strip temperature for different slab thicknesses.

Mansouri et $a .^{21)}$ developed a computer code to obtain the temperature distribution of the hot steel strip transfer table between the last roughing shelf and the first finishing shelf. The authors considered radiation and convection from the top, bottom and surrounding surfaces of the strip, and by considering the conduction inside it. The predicted 
temperature distributions were compared with the measured one. Also, they investigated the effects of the thermal shield and heat source. They concluded that the thermal shield and heat source reduced the heat loss.

Zhang et $a .^{22)}$ developed 1.5D finite element model to calculate the temperature distribution of the hot steel strip. The results were compared with the experimental data. The model had an excellent performance in both accuracy and calculation speed and was applied to control the cooling uniformity in plate width direction. The temperature uniformity of cooling in plate width was enhanced.

The objective of this study is to investigate the effects of the thermal shield with respect to its emissivity and initial temperature. The modeling is developed to calculate the temperature variation of the hot steel strip considering conduction, convection and radiation heat transfer with commercial software ANSYS Fluent. The lab-scale experiment for measuring the temperature of hot strip is performed. The results are compared with the calculated one to validate the modeling. For the practical purposes, the temperature variation and distribution of the hot steel strip between roughing and finishing mills is identified by the modeling. The temperature drop due to the heat losses is investigated for different the emissivity and initial temperature of the thermal shield. Finally, the geometry of the thermal shield is optimized to reduce heat losses.

\section{Experiment and Modeling}

\subsection{Experimental Setup}

Figure 1(a) shows the geometry of the steel strip sample for lab scale experiments. The sample has square shape with $0.3 \mathrm{~m}$ width and $0.03 \mathrm{~m}$ thickness. It has drilled holes for thermocouples to measure the temperature of the steel strip while the depth of the holes is $0.01 \mathrm{~m}$. Figure 1(b) shows the picture of the hot steel strip sample for temperature measurement. It is heated up to $900^{\circ} \mathrm{C}$ in the furnace. Thermocouples are inserted to the holes to measure the temperature of the

(a)

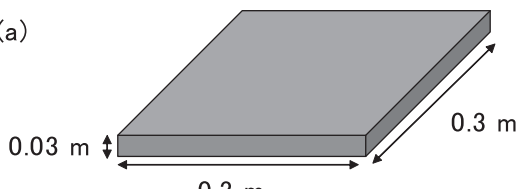

$0.3 \mathrm{~m}$

(b)

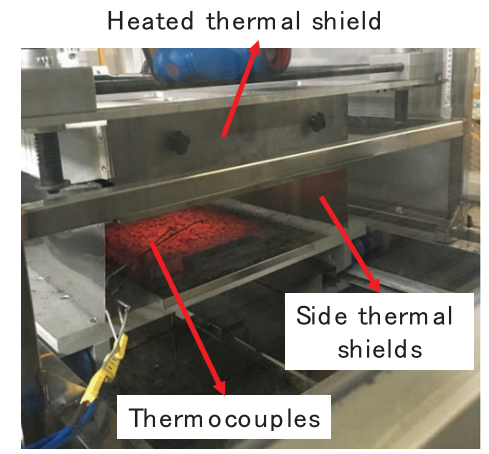

Fig. 1. Experimental setup for measurement of the temperature drop (a) geometry of the hot steel strip sample (b) picture of thermal shield apparatus and measurement. (Online version in color.) hot steel strip sample. Then, the sample is moved to the thermal shield apparatus. The temperature of the hot steel strip sample is measured for 180 seconds. The temperature drop of the hot steel strip sample with the heat losses is investigated for the different material and emissivity of thermal shields. Two thin steel thermal shields are on the side of the hot steel strip while the heated thermal shield is on the top. The thickness of the thermal shield is $0.005 \mathrm{~m}$. The initial temperature is $30^{\circ} \mathrm{C}$ without heating or $400^{\circ} \mathrm{C}$ with heating. The temperature of the thermal shield increases due to the heat transfer from the hot steel strip sample. Therefore, the temperature of the thermal shield is investigated.

\subsection{Geometry of Modeling}

The numerical simulation of temperature distribution and drop as function of time is required to reduce the heat losses. In this study, the numerical modeling is developed to predict the temperature of the hot steel strip. Figure 2(a) shows the geometry of the modeling to predict the temperature variation of the hot steel strip sample compared with experimental results for validation of the modeling. The geometry of modeling is based on the experimental setup. The hot steel strip and the thermal shield on the top have the thickness to predict their temperature changes. However, the thickness of thin thermal shields on the side is not considered for simplicity so that its temperature changes are not investigated.

Another geometry is considered to predict the tempera-

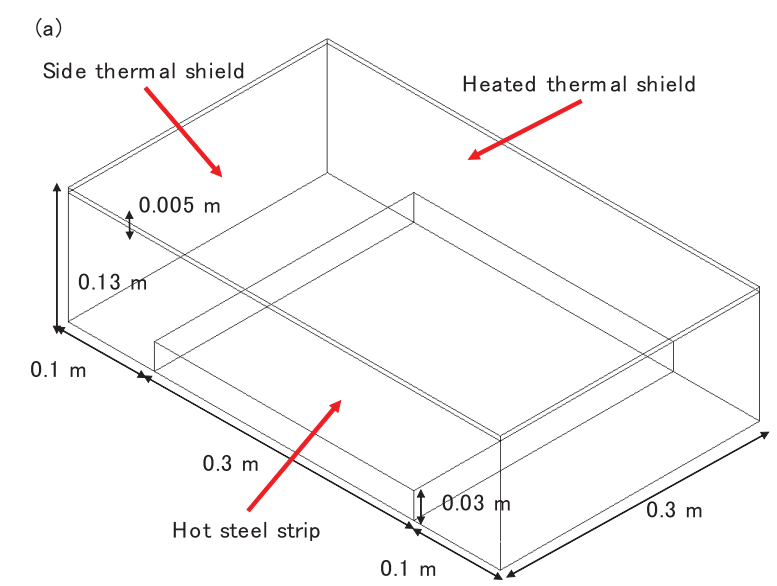

(b)

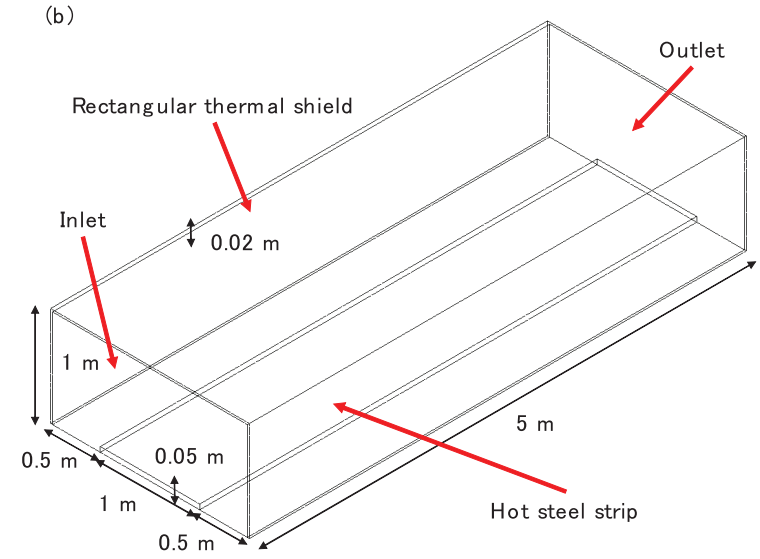

Fig. 2. Schematic diagrams of the modeling to predict the temperature variation of the hot steel strip for (a) experiment setup and (b) between roughing and finishing mills. (Online version in color.) 
ture distribution of the hot steel strip between roughing and finishing mills for the practical purposes. The distance between roughing and finishing mills is about $75 \mathrm{~m}$ while the hot steel strip moves at a velocity $0.5 \mathrm{~m} / \mathrm{s}$. Figure 2(b) shows the geometry of the modeling to predict the temperature variation of the hot steel strip between roughing and finishing mills. It is assumed that the velocity of air in the inlet is $0.5 \mathrm{~m} / \mathrm{s}$ and the length of the hot steel strip is 5 $\mathrm{m}$ for numerical modeling and simplicity. The temperature drop of the hot steel strip and thermal shield is calculated for 150 seconds. The different emissivities and geometries of the thermal shields are investigated to decrease the heat loss and temperature drop of the hot steel strip.

\section{Governing Equations and Boundary Conditions}

Conduction, convection and radiation are considered to predict the temperature variation and distribution of the hot steel strip between roughing and finishing mills. The convection heat transfer can be forced or natural convection. Newtonian incompressible fluid is considered and all properties of the fluid are assumed to be constant except the density of fluid changes with temperature for natural convection. Continuity equation is expressed as

$$
\nabla \cdot \vec{V}=0
$$

where $\vec{V}$ is velocity vector. Momentum equation is expressed as

$$
\rho\left(\frac{\partial \vec{V}}{\partial t}+(\vec{V} \cdot \nabla) \vec{V}\right)=-\nabla p+\mu \nabla^{2} \vec{V}+\rho \vec{g}
$$

where $\rho, p, \mu$, and $\vec{g}$ are the density, pressure, viscosity and gravitational acceleration, respectively. In order to consider buoyancy effect and natural convection, the density of the air is determined by incompressible ideal gas law so that the density difference with respect to the temperature is applied to the momentum equation. Energy equation is expressed as

$$
\rho c_{p}\left(\frac{\partial T}{\partial t}+(\vec{V} \cdot \nabla) T\right)=k \nabla^{2} T
$$

where $c_{p}, T$ and $k$ are the specific heat capacity, temperature and thermal conductivity, respectively. The energy equation describes the conduction inside the hot steel with zero velocity. The viscosity, specific heat capacity and thermal conductivity of the air are equal to $1.7894 \times 10^{-5} \mathrm{~kg} / \mathrm{m} \cdot \mathrm{s}$, $1006.43 \mathrm{~J} / \mathrm{kg} \cdot \mathrm{K}, 0.0242 \mathrm{~W} / \mathrm{m} \cdot \mathrm{K}$, respectively. The density, specific heat capacity and thermal conductivity of the hot steel strip are equal to $8030 \mathrm{~kg} / \mathrm{m}^{3}, 502.48 \mathrm{~J} / \mathrm{kg} \cdot \mathrm{K}, 16.27 \mathrm{~W} /$ $\mathrm{m} \cdot \mathrm{K}$, respectively. The surface-to-surface model with view factors is employed to analyze the radiation heat transfer without considering participating medium. The view factor of two surface area $A_{i}$ and $A_{j}$ at a distance $S$ is defined as ${ }^{23)}$

$$
F_{A_{i}-A_{j}}=\frac{1}{A_{i}} \int_{A_{i}} \int_{A_{j}} \frac{\cos \theta_{i} \cos \theta_{j}}{\pi S^{2}} d A_{j} d A_{i}
$$

where $\theta_{i}$ and $\theta_{j}$ are the angles between the surface normal and a ray between the two surfaces while $S$ is the length of the ray. The radiosity of surface $i$ is written by ${ }^{23}$ )

$$
J_{i}=E_{i}+(1-\varepsilon) \sum_{j=1}^{N} F_{A_{i}-A_{j}} J_{j}
$$

where $E_{i}$ is the emissive power of the surface $i$ while $\varepsilon$ is emissivity of surface $i$. The emissivity of hot steel strip is assumed to be $0.8 .^{21)}$

The convection and radiation heat transfer are applied to the surfaces facing the surrounding outside computational domain in Figs. 2(a) and 2(b) as their boundary conditions. The external convection heat transfer coefficient is assumed to be $10 \mathrm{~W} / \mathrm{m}^{2} \cdot \mathrm{K}$. The external emissivity of the surrounding is also assumed to be 0.9 . In addition, the temperature of the external free stream and surrounding is assumed to be $30^{\circ} \mathrm{C}$. The boundary condition of the open sides in Fig. 2(a) is atmospheric pressure. The natural convection is considered in the geometry of Fig. 2(a). On the other hand, the forced convection is considered in the geometry of Fig. 2(b) so that the inlet velocity is $0.5 \mathrm{~m} / \mathrm{s}$. The atmospheric pressure is applied to the outlet has as a boundary condition. At interface between the hot steel and air, the velocity boundary condition is no slip condition so that the velocity of the contact fluid layer is stationary. In addition, the thermal boundary conduction at the interface is expressed as

$$
\dot{q}_{\text {convection }}=\dot{q}_{\text {conduction }}=-\left.k_{\text {fluid }} \frac{\partial T}{\partial y}\right|_{\text {interface }}
$$

because the heat transfer from the solid to the stationary fluid layer is pure conduction.

\section{Results}

\subsection{Model Prediction Compared with the Experiments}

The steel, aluminum and inconel thermal shields are considered for experiments. Their different emissivities are focused on in this study. Also, heated steel thermal shield at its initial temperature $400^{\circ} \mathrm{C}$ with heating is employed to study the effects of the temperature of the thermal shield. The temperature variation of the hot steel strip is measured below $0.01 \mathrm{~m}$ from its upper surface. Figure 3(a) shows the experimental measurement of the temperature variation of the hot steel strip sample shown in Fig. 2(a) without the shield and with the steel, aluminum, inconel and heated steel shields for 180 seconds. The temperature differences among them are similar at the beginning of the cooling. However, the hot steel strip sample without the thermal shield has the largest temperature drop at the end of cooling. Therefore, the thermal shield can reduce the temperature drop of the hot steel strip sample. In addition, the hot steel strip sample with the heated steel thermal shield at the initial temperature $400^{\circ} \mathrm{C}$ has smaller temperature drop than that with the steel thermal shield without heating. The high temperature of the thermal shield reduces the temperature drop of the hot steel strip sample. The differences between the steel, aluminum and inconel thermal shields are caused by the different emissivity of the thermal shields. Also, Fig. 3(b) shows the model prediction of the temperature variation of the hot steel strip samples shown in Fig. 2(a) without the shield and with the steel, aluminum, inconel and heated steel shields for 180 seconds. The numbers of nodes and elements used for the predictions are 129642 and 120000 , respectively. The grid sensitivity analysis is performed with increasing the number of nodes and elements, and decreasing the nodes spacing until the average temperature difference is less than $1 \%$. Here, the emissivities of the steel, aluminum and inconel thermal 
(a)

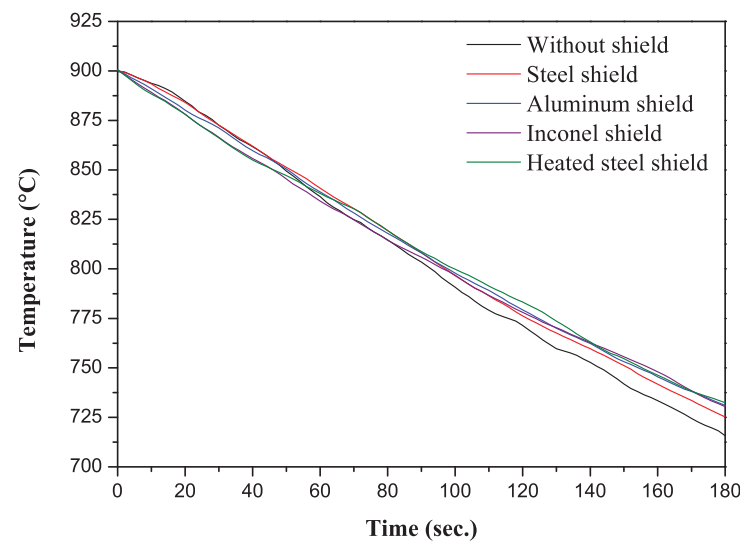

(b)

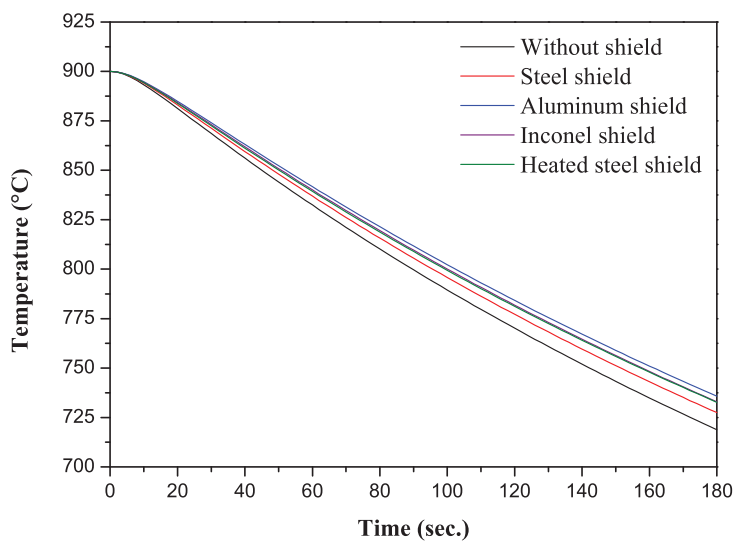

Fig. 3. The temperature variation of (a) experimental measurement and (b) model prediction for the hot steel strip sample for 180 seconds. (Online version in color.)

shields are assumed to be $0.6,{ }^{24)} 0.3^{25)}$ and $0.4,{ }^{26)}$ respectively. The emissivities of the heated steel thermal shield is also assumed to be $0.6{ }^{24)}$ The predicted results are similar to the experimental results. The relative error of the temperature after 180 seconds is less than $1 \%$ between experimental and prediction results. The hot steel strip sample without thermal shield has the largest temperature drop among them as mentioned above. In addition, the hot steel strip sample with aluminum thermal shield has the smallest temperature drop because of its low emissivity. The comparison of the experimental measurement and model prediction of the temperature hot steel strip samples for different thermal shields are presented in Table 1. The hot steel strip sample with heated steel thermal shield has the minimum average rate of temperature drop $0.93^{\circ} \mathrm{C} / \mathrm{s}$ in experimental results. Besides, the hot steel strip with aluminum thermal shield has the minimum average rate of temperature drop $0.91{ }^{\circ} \mathrm{C} / \mathrm{s}$ in prediction results. However, it is noticed that the thermal shields with low emissivity can reduce the temperature drop comparing the steel, aluminum and inconel thermal shields for both experimental and prediction results. Also, it is obvious that high temperature of the thermal shield reduces the temperature drop of the hot steel strip. Figure 4 shows the model prediction results of the temperature variation of different thermal shields. The location of the temperature prediction is the center of the surface facing the hot steel strip. The temperature of the thermal shield increases due to the incoming radiation from
Table 1. The comparison of the experimental measurement and model prediction of the hot steel strip sample with different thermal shields.

\begin{tabular}{|c|c|c|c|c|}
\hline & \multicolumn{2}{|c|}{ Experiment } & \multicolumn{2}{|c|}{ Prediction } \\
\hline & $\begin{array}{c}\text { Temperature } \\
\text { after } 180 \\
\text { seconds }\left({ }^{\circ} \mathrm{C}\right)\end{array}$ & $\begin{array}{c}\text { Average rate } \\
\text { of temperature } \\
\text { drop }\left({ }^{\circ} \mathrm{C} / \mathrm{s}\right)\end{array}$ & $\begin{array}{c}\text { Temperature } \\
\text { after } 180 \\
\text { seconds }\left({ }^{\circ} \mathrm{C}\right)\end{array}$ & $\begin{array}{c}\text { Average rate } \\
\text { of temperature } \\
\text { drop }\left({ }^{\circ} \mathrm{C} / \mathrm{s}\right)\end{array}$ \\
\hline $\begin{array}{l}\text { Without } \\
\text { thermal shield }\end{array}$ & 715 & 1.02 & 718 & 1.00 \\
\hline $\begin{array}{l}\text { Steel thermal } \\
\text { shield }\end{array}$ & 725 & 0.97 & 727 & 0.96 \\
\hline $\begin{array}{l}\text { Aluminum } \\
\text { thermal shield }\end{array}$ & 731 & 0.94 & 735 & 0.91 \\
\hline $\begin{array}{c}\text { Inconel } \\
\text { thermal shield }\end{array}$ & 730 & 0.94 & 732 & 0.93 \\
\hline $\begin{array}{l}\text { Heated steel } \\
\text { thermal shield }\end{array}$ & 732 & 0.93 & 732 & 0.93 \\
\hline
\end{tabular}

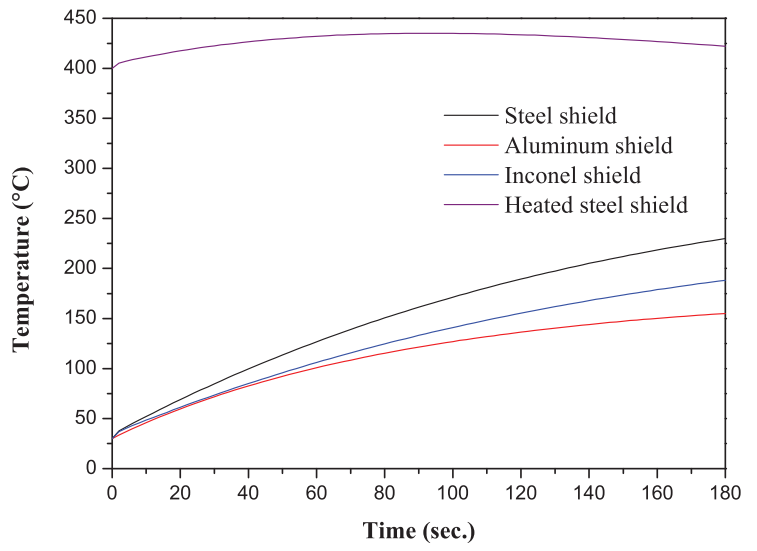

Fig. 4. The predicted temperature variation of the different thermal shields for 180 seconds. (Online version in color.)

the hot steel strip. It depends on the emissivity of the thermal shield so that high emissivity makes the thermal shield absorb more incoming radiation. The steel thermal shield with emissivity 0.6 has higher temperature than that of other thermal shields. The low emissivity increases the reflectivity of the thermal shield for incoming radiation from the hot steel strip. Therefore, the aluminum thermal shield with emissivity 0.3 has the smallest temperature. In addition, the temperature of the thermal shields affects the temperature variation of the hot steel strip. The temperature of the heated steel thermal shield increases from its initial temperature $400^{\circ} \mathrm{C}$. It has the highest temperature $450^{\circ} \mathrm{C}$ after 45 seconds and then its temperature decreases because the temperature of the hot steel strip decreases. The temperature of the hot steel strip with heated steel thermal shield is higher than that with the steel thermal shield without heating. The thermal shield at high temperature emits more radiation to hot steel strip so that it helps the temperature drop of the hot steel strip decrease. Finally, the heat loss from upper surface of the hot steel strip is calculated and presented in Table 2. The radiative heat loss is about $90 \%$ of total heat loss for without and with thermal shields. The radiative heat loss decreases with low emissivity of the thermal shield whereas convective heat losses are the same about $300 \mathrm{~W}$ for all cases. Thus, the radiative heat transfer is dominant and the emissivity of the thermal shield is important parameter to reduce the heat loss of the hot steel strip. 
Table 2. The calculated the heat loss without and with different thermal shields.

\begin{tabular}{cccccc}
\hline & $\begin{array}{c}\text { Without } \\
\text { thermal } \\
\text { shield }\end{array}$ & $\begin{array}{c}\text { Steel } \\
\text { thermal } \\
\text { shield }\end{array}$ & $\begin{array}{c}\text { Aluminum } \\
\text { thermal } \\
\text { shield }\end{array}$ & $\begin{array}{c}\text { Inconel } \\
\text { thermal } \\
\text { shield }\end{array}$ & $\begin{array}{c}\text { Heated steel } \\
\text { thermal } \\
\text { shield }\end{array}$ \\
\hline $\begin{array}{c}\text { Radiative } \\
\text { heat loss (W) }\end{array}$ & 3748 & 3447 & 3210 & 3299 & 3225 \\
$\begin{array}{c}\text { Convective } \\
\text { heat loss (W) } \\
\text { Total heat } \\
\text { loss (W) }\end{array}$ & 304 & 311 & 306 & 298 & 327 \\
\hline
\end{tabular}

\subsection{Design of the Thermal Shield between Roughing and Finishing Mills}

The temperature variation of hot steel strip between roughing and finishing mills shown in Fig. 2(b) is predicted for practical purposes. The standard $\mathrm{k}-\varepsilon$ model is employed to describe the turbulence flow because the inlet velocity is 0.5 $\mathrm{m} / \mathrm{s}$ and Reynolds number is about 45000 . The turbulent Prandtl number is 0.85 and the mesh size adjacent to the hot steel strip is about $0.003 \mathrm{~m}$. The forced convection is considered so that the buoyancy effect is neglected and the density of air is assumed to $1.225 \mathrm{~kg} / \mathrm{m}^{3}$. The boundary conditions are the same as those for the experiment except that the bottom of the hot steel strip is insulated to reduce the temperature drop. Moreover, it is assumed that the thermal shield has steady state temperature because of the continuous rolling process. The temperature variation of hot steel strip is predicted at the center of the hot steel strip below $0.01 \mathrm{~m}$ from the upper surface. The aluminum thermal shields with different emissivities, dimensions and geometries are considered to identify the effects of thermal shield on the temperature variation of the hot steel strip. The numbers of nodes and elements used for the rectangular thermal shield with height $1 \mathrm{~m}$ are 355940 and 335800 respectively. Other prediction cases have the similar number of nodes and elements depending on their dimension and geometry. The grid sensitivity analysis for all cases is performed with increasing the number of nodes and elements and decreasing the nodes spacing until the average temperature difference is less than $1 \%$. Figure 5 shows the predicted temperature variation of the hot steel strip between roughing and finishing mills with the rectangular thermal shields for height 1 and $0.5 \mathrm{~m}$ and emissivity 0.5 and 0.1 . The low emissivity of the rectangular thermal shield with height $1 \mathrm{~m}$ reduces the temperature drops as expected in section 4.1. Also, the height $0.5 \mathrm{~m}$ of the rectangular thermal shield reduces the temperature drop. The steady state temperatures of the thermal shields with height 1 and $0.5 \mathrm{~m}$ are 281 and $339^{\circ} \mathrm{C}$, respectively. The small volume of the thermal shield increases its temperature due to the small heat capacity. The high temperature of the thermal shield decreases the temperature drop of the hot steel strip. It is noticed that the thermal shield needs to have low emissivity and small volume to reduce the temperature drop of the hot steel strip. Figure 6 shows the predicted temperature variation of the hot steel strip between roughing and finishing mills for rectangular, circular and triangular geometries of the thermal shields with emissivity 0.1 and height 1 and $0.5 \mathrm{~m}$. The geometry of the circular thermal shield has half circle and radius $1 \mathrm{~m}$. Also, the geometry of the triangular thermal shield has isosceles triangle and height $1 \mathrm{~m}$ or $0.5 \mathrm{~m}$. All thermal shield has the

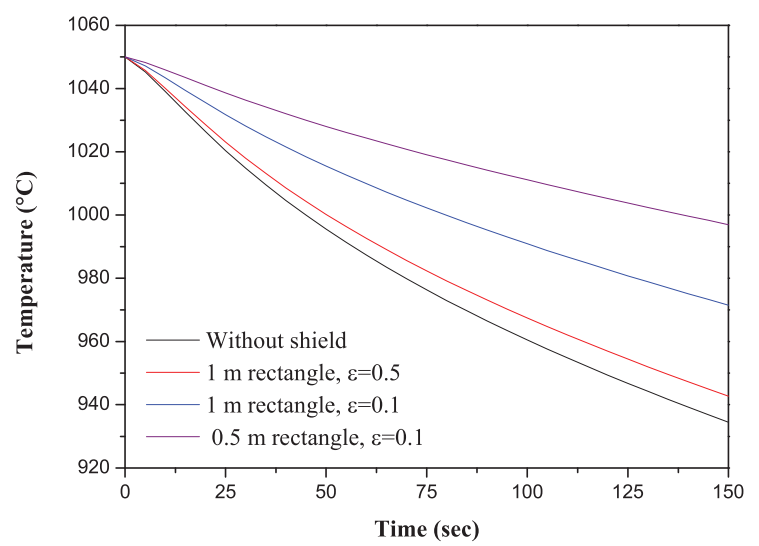

Fig. 5. The predicted temperature variation of the hot steel strip between roughing and finishing mills with the rectangular thermal shields for height $1 \mathrm{~m}$ and $0.5 \mathrm{~m}$ and emissivity 0.5 and 0.1 . (Online version in color.)

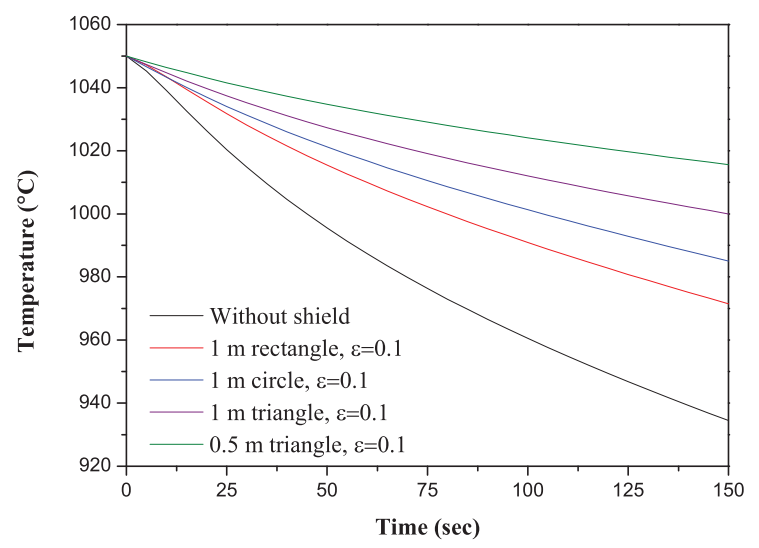

Fig. 6. The predicted temperature variation of the hot steel strip between roughing and finishing mills for rectangular, triangular and circular geometries of the thermal shields with emissivity 0.1 and height 1 and $0.5 \mathrm{~m}$. (Online version in color.)

same width $2 \mathrm{~m}$ and length $5 \mathrm{~m}$. The temperature and average rate of temperature drop without thermal shield after 150 seconds is $934^{\circ} \mathrm{C}$ and $0.77^{\circ} \mathrm{C} / \mathrm{s}$, respectively. The triangular thermal shield with height $1 \mathrm{~m}$ has the highest temperature of the hot steel strip after 150 seconds among other thermal shield with height $1 \mathrm{~m}$. The reason is that it has smaller volume than that of rectangular and circular thermal shield. The steady state temperatures of the thermal shields for rectangular, circular and triangular geometries at height $1 \mathrm{~m}$ are 281 , 323 and $350^{\circ} \mathrm{C}$, respectively. Isosceles triangle has the smallest volume at a given height of the thermal shield. In addition, the temperature drop can be reduced when the height of the triangular thermal shield is $0.5 \mathrm{~m}$. Therefore, the thermal shield needs isosceles triangular geometry with low emissivity for the best performance. The temperature and average rate of temperature drop for the hot steel strip with $0.5 \mathrm{~m}$ height triangular thermal shield after 150 seconds is $1015^{\circ} \mathrm{C}$ and $0.23^{\circ} \mathrm{C} / \mathrm{s}$, respectively. Figure 7 (a) shows the predicted temperature distribution at cross section of the center of the hot steel strip with triangular thermal shield for emissivity 0.1 after 150 seconds. The temperature distribution inside the hot steel strip can be investigated using this model prediction. Figure 7(b) shows the predicted temperature distribution at upper surface of the hot steel strip with triangular thermal 
(a)

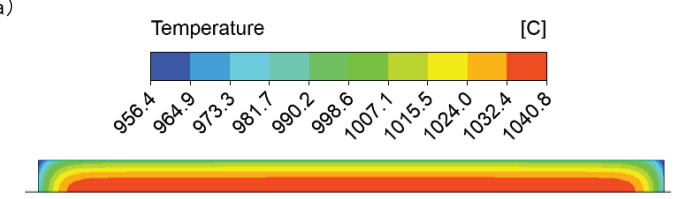

(b)

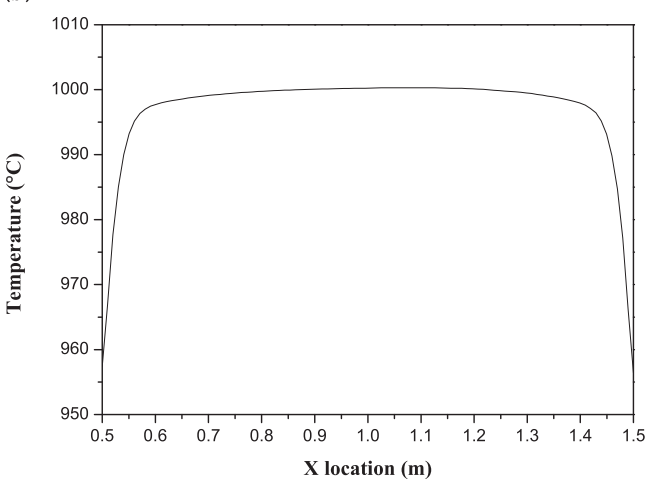

(c)

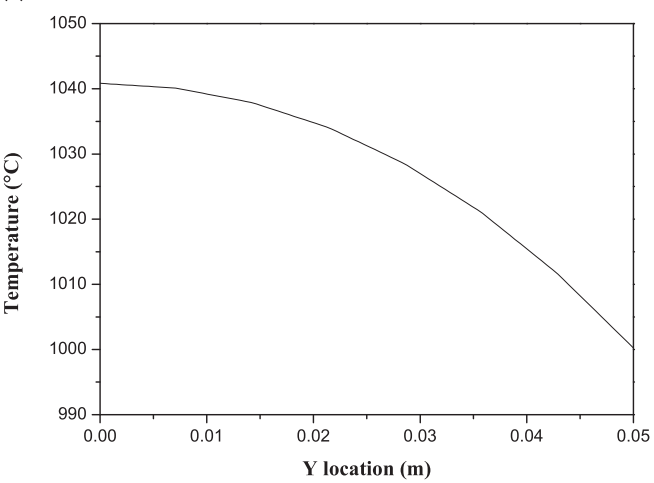

Fig. 7. The predicted temperature distribution after 150 seconds (a) at cross section of the center of the hot steel strip (b) at horizontal line of the center of the hot steel strip (c) at vertical line of the center of the hot steel strip with triangular thermal shield for emissivity 0.1 . (Online version in color.)

shield for emissivity 0.1 after 150 seconds. The temperature at the edge is quite smaller than that at the center of the hot steel strip. The temperature difference between the edge and center is about $40^{\circ} \mathrm{C}$. Figure $7(\mathrm{c})$ shows the predicted temperature distribution at vertical line of the center of the hot steel strip with triangular thermal shield for emissivity 0.1 after 150 seconds. The temperature drop of the bottom surface is about $10^{\circ} \mathrm{C}$ because of the insulation. Also, the temperature difference between the bottom and upper surface is about $40^{\circ} \mathrm{C}$. Based on the model prediction, nonuniformity of the temperature in hot steel strip can be identified. Also, the results can be employed to achieve the uniformity of the temperature and mechanical properties of the steel strip.

\section{Conclusion}

The experiment and modeling are conducted to investigate the effects of the thermal shield with respect to its emissivity and initial temperature. The model prediction considers conduction, convection and radiation heat transfer. The temperature variation of the hot steel strip is measured and compared with the results of the model prediction with and without the thermal shields for the validation. Also, the temperature variation and distribution of the hot steel strip between roughing and finishing mills is predicted. The different emissivities and geometries of the thermal shields are investigated. The thermal shield with low emissivity reduces the temperature drop of the hot steel strip because of high reflectivity of the thermal shield. Also, the thermal shield with small volume and high temperature reduce the temperature drop of the hot steel strip due to emitting more radiation from the thermal shield. The isosceles triangle is the best geometry to reduce the temperature drop of the hot strip. The average rate of temperature drop can be reduced from $0.77^{\circ} \mathrm{C} / \mathrm{s}$ without thermal shield to $0.23^{\circ} \mathrm{C} / \mathrm{s}$ with triangular thermal shield with emissivity 0.1 and height $0.5 \mathrm{~m}$. The results and model predictions improve the temperature drop and uniformity of the hot steel strip between roughing and finishing mills.

\section{REFERENCES}

1) C. H. Moon and Y. Lee: Int. J. Heat Mass Transf., 55 (2012), No. 1-3, 310. https://doi.org/10.1016/j.ijheatmasstransfer.2011.09.019

2) J. Kim, J. Lee and S. M. Hwang: Int. J. Heat Mass Transf., 52 (2009), No. 7-8, 1864. https://doi.org/10.1016/j.ijheatmasstransfer.2008.10.013

3) H. Honjo, S. Yusa, M. Mikami, M. Yamaguchi and H. Ishii: IHI Eng. Rev., 42 (2009), No. 1, 32.

4) C. J. Park, K. S. Yoon and C. H. Lee: J. Mech. Sci. Technol., 24 (2010), No. 5, 1011. https://doi.org/10.1007/s12206-010-0317-4

5) M. Bagheripoor and H. Bisadi: Appl. Therm. Eng., 31 (2011), No. 10, 1556. https://doi.org/10.1016/j.applthermaleng.2011.01.005

6) S. M. Belskiy, S. Yankova, V. B. Chuprov, K. V. Bakhaev and A. O. Stoyakin: J. Chem. Technol. Metall., 50 (2015), No. 6, 613.

7) P. Laurinen and J. Röning: J. Mater. Process. Technol., 168 (2005), No. 3, 423. https://doi.org/10.1016/j.jmatprotec.2004.12.002

8) M. Jiang, X. Li, J. Wu and G. Wang: Int. J. Heat Mass Transf., 78 (2014), 967. https://doi.org/10.1016/j.ijheatmasstransfer.2014.07.061

9) H. Sayadi and S. Serajzadeh: Prod. Eng., 9 (2015), No. 1, 79. https:// doi.org/10.1007/s11740-014-0577-4

10) J. G. Kim and K. Y. Huh: ISIJ Int., 40 (2000), No. 11, 1115. https:// doi.org/10.2355/isijinternational.40.1115

11) S. Serajzadeh: Appl. Math. Model., 27 (2003), No. 11, 861. https:// doi.org/10.1016/S0307-904X(03)00085-4

12) G. Tang, B. Wu, D. Bai, Y. Wang, R. Bodnar and C. Zhou: Appl. Therm. Eng., 132 (2018), 779. https://doi.org/10.1016/j. applthermaleng.2018.01.017

13) P. Pirouznia, N. Å. I. Andersson, A. Tilliander and P. G. Jönsson: Metals, 9 (2019), No. 6, 675. https://doi.org/10.3390/met9060675

14) S. X. Zhou: J. Mater. Process. Technol., 134 (2003), No. 3, 338. https://doi.org/10.1016/S0924-0136(02)01118-4

15) A. Mukhopadhyay and S. Sikdar: J. Mater. Process. Technol., 169 (2005), No. 2, 164. https://doi.org/10.1016/j.jmatprotec.2005.04.039

16) K. Speicher, A. Steinboeck, D. Wild, T. Kiefer and A. Kugi: IFAC Proc. Vol., 46 (2013), 409. https://doi.org/10.3182/201308254-US-2038.00006

17) A. Gołdasz, Z. Malinowski, B. Hadała and M. Rywotycki: Arch. Metall. Mater., 60 (2015), No. 1, 275. https://doi.org/10.1515/ amm-2015-0044

18) V. Panjkovic: Appl. Therm. Eng., 27 (2007), 2404. https://doi. org/10.1016/j.applthermaleng.2007.03.009

19) H. N. Han, J. K. Lee, H. J. Kim and Y. S. Jin: J. Mater. Process. Technol., 128 (2002), 216. https://doi.org/10.1016/S0924-0136(02)00454-5

20) R.-b. Mei, C.-s. Li, X.-h. Liu and B. Han: J. Iron Steel Res. Int., 17 (2010), 17. https://doi.org/10.1016/S1006-706X(10)60052-0

21) N. Mansouri, M. Mirhosseini and A. Saboonchi: Appl. Therm. Eng., 38 (2012), 91. https://doi.org/10.1016/j.applthermaleng.2011.12.049

22) T. Zhang, L. Xiong, Y. Tian, B. Wang and Z. Wang: ISIJ Int., 57 (2017), No. 4, 770. https://doi.org/10.2355/isijinternational. isijint-2016-477

23) M. F. Modest: Radiative Heat Transfer, Elsevier, New York, (2013). https://doi.org/10.1016/C2010-0-65874-3

24) M. Švantner, P. Vacíková and M. Honner: Infrared Phys. Technol., 61 (2013), 20. https://doi.org/10.1016/j.infrared.2013.07.005

25) H. Luo, X. Zhang, S. Huang, D. Shan, L. Deng, L. He, J. He, Y. Xu, H. Chen and C. Liao: Infrared Phys. Technol., 99 (2019), 123. https:// doi.org/10.1016/j.infrared.2019.04.013

26) M. Balat-Pichelin, J. L. Sans, E. Bêche, V. Flaud and J. Annaloro: Mater. Charact., 127 (2017), 379. https://doi.org/10.1016/j. matchar.2017.02.016 